\title{
The Nonlinear Relationship Between Terrorism and Poverty
}

\author{
Walter Enders and Gary A. Hoover \\ University of Alabama \\ Department of Economics, Finance, and Legal Studies \\ Box 870224 \\ Tuscaloosa, AL 35487-0224
}

It is tempting to argue that poor economic circumstances are a precursor to terrorist activities. After all, economic theory suggests that it would be easier for a terrorist group to recruit lowincome or unemployed individuals since they have a relatively low opportunity cost of time. Moreover, as argued by Crenshaw (1981), people who believe that their economic prospects have been limited by others might have grievances that could attract them to terrorism. The fact that most terrorist attacks are staged in low income countries seems to support the notion that poverty causes terrorism. However, empirical papers such as Krueger and Maleckova (2003), Abadie (2006) and Piazza (2006) argue that it is a lack of political freedoms, and not poverty, that is responsible for terrorism. In the presence of other variables (such as a measure of civil liberties), they find that the level of terrorism is not significantly affected by per capita GDP. These findings were supported by Gassebner and Luechinger's (2011) meta study: almost every one of the 13.4 million different regressions estimated using various combinations of the 65 variables contained in 43 different studies indicate no significant causal effects between terrorism and per capita GDP. The two robust explanatory variables for terrorism were found to be population and various measures of democratic freedom, but not per capita GDP.

We add to the large and growing literature on the relationship between terrorism and poverty in two different ways. First, unlike previous studies, we are able to use a data set that decomposes the number of terrorist incidents into domestic and transnational incidents. We show that poverty has a very distinct effect on each type of terrorism. Second, we use split sample and logistic modeling techniques to allow for the possibility that the relationship between terrorism and poverty is nonlinear. When we account for the nonlinearities in the data and distinguish between the two types of terrorist events, we find that poverty has as a very strong influence on domestic terrorism and a small, but significant, effect on transnational terrorism. Studies that examine terrorism only in a linear framework fail to capture the nonlinear relationship between terrorism and poverty. Moreover, pooling the two types of terrorism hides the distinct underlying nonlinear relationship present in each type.

\section{Introduction}

There are good reasons to suppose that the relationship between terrorism and poverty is likely to be nonlinear. Clearly, very little terrorism is spawned in the very poorest of countries or in the 
very richest. One explanation is that there is little surplus to support terrorism in the poorest countries and that high income countries have the resources to thwart terrorism. Moreover, the literature on the economics of crime strongly supports the notion that an individual's economic circumstances have a nonlinear (or ambiguous) effect on participation in crime. In an early study, Block and Heineke (1975) show that an increase in income from legal activities will generally decrease an individual's crime related activities because of increased foregone earnings. However, if the increase applies to all agents, the expected return to participation in crime

increases so that income and criminal activities can move in the same direction. Clearly, a number of terrorist groups have been able to finance many of their activities by robbery and/or by kidnapping high-income individuals. On the empirical side, Muroi and Baumann (2009) find that wealth has an positive effect on crime in low income countries but a negative effect on crime in wealthier counties. In a similar vein, Brush (2007) and Choe (2008) find that income inequality (not simply the level of income) acts to increase crime.

To our knowledge, all of the studies on terrorism and poverty use only data on transnational incidents, data that pools domestic and transnational incidents, or incidents within a single country or region (such as the Palestinian Territory or Corsica). Certainly, a major reason for this focus is on data availability. However, using a new data set from Enders, Sandler and Gaibulloev, ESG, (2011), we are able to separately examine how both domestic and transnational terrorism change with economic circumstances. To date, no other paper has explored the likely differences between two types of terrorism in regard to the influences of income and civil liberties. Yet, there are important reasons to differentiate between the two types of terrorism. Not only is there far more domestic terrorism than transnational terrorism (see Figure 1 below), the motives of transnational terrorists will generally differ from those conducting only domestic attacks. Moreover, with transnational incidents, it is sometimes unclear which nation's poverty level is the most appropriate to use in the empirical analysis. For example, the so-called Underwear Bomber (Umar Farouk Abdulmutallab), was a Nigerian operative for al Qaeda in the Arabian Peninsula attempting to blow up an airplane en route from Amsterdam to Detroit.

\section{The Data}

The National Consortium for the Study of Terrorism and Responses to Terrorism (START) maintains the Global Terrorism Database (GTD) for the U.S. Department of Homeland Security. The Start (2009) codebook indicates that the data set describes 82,536 terrorist incidents that occurred during the 1970-2007 period. For each incident, the date, location, type of attack, and the number of deaths and casualties is reported. Although the data set is quite rich, there is no variable that distinguishes whether the incident was domestic or transnational. However, as ESG point out, with domestic, or homegrown, terrorism, the nationalities of the victim and perpetrators are the same as the location of the attack. Transnational terrorism, on the other hand, has transboundary effects. The essence of ESG's methodology was to compare the nationalities of the victims and perpetrators with the location of the event. If all matched, the incident was 
deemed to be a domestic terrorist incident. If at least one of the nationalities differed from the location, the incident was coded as transnational. Since the reporting and coding methods used to construct the GTD changed over time, in this paper we use only incidents containing at least one death since such death incidents tend to be recorded most accurately. All of the remaining variables used in this analysis comes from the World Development Indicators (WDI) comprised and cataloged by the World Bank. It is freely accessible online at: http://www.worldbank.org.

\section{Examining Nonlinearity}

Figure 1 shows the relationship between the alternative terrorism measures and real per capita GDP. In Panel 1, the y-axis is the number of domestic incidents and the x-axis is the level of real per capita GDP. Although most countries experienced no domestic terrorism, the countries that did experience terrorism tend to have low income levels. In order that the relationship between terrorism and income be shown more clearly, Panel 2 truncates the $\mathrm{x}$-axis at $\$ 10,000$. Panels 3 and 4 show analogous scatter plots for transnational terrorism.

For our purposes, there are two clear observations to be gleaned from the four panels. First, the relationship between terrorism and income level is clearly nonlinear. Terrorist incidents are clustered in the relatively low income countries whereas the high-income countries have almost no terrorism. For these high-income countries, further increases in income levels do not seem to have any effect on the level of terrorism. Second, the usual normality assumption is inappropriate since most counties experience no more than a single incident. Instead, the incident series are best estimated as counts using the Poisson or negative binomial distributions. If the mean of the process is properly specified, quasi-maximum likelihood estimates that ignore the fact the dependent variable is a count can be asymptotically unbiased. However, the estimates are inefficient and the standard errors are incorrect so that inference is problematic.

We classified the 172 countries in our sample into the four World Bank categories of Low Income, Lower Middle Income, Upper Middle Income, and High Income as of 2007. Of the 97 countries in the lowest two groups, 64 had fewer than five domestic incidents (so that 33 had 5 or more incidents). Of the other 75 countries in the upper two income groups, 67 had fewer than five domestic incidents (so that the other 12 had 8 or more incidents). Hence, using 5 as the threshold, or cutoff value, the sample value of $\chi^{2}$ for the null hypothesis of no difference in the incident totals across the income classes is 12.71 with a prob-value of 0.00036 . Similar calculations for domestic incidents and for other cutoff values are given by: 


\begin{tabular}{|c|c|c|c|c|}
\hline \multirow[b]{2}{*}{ Cutoff } & \multicolumn{2}{|c|}{ Domestic } & \multicolumn{2}{|c|}{ Transnational } \\
\hline & Lowest & Highest & Lowest & Highest \\
\hline$\underline{\text { Value }}$ & Incomes & Incomes & $\underline{\text { Incomes }}$ & Incomes \\
\hline$<2$ & 52 & 63 & 67 & 67 \\
\hline \multirow[t]{2}{*}{$>=2$} & 45 & 12 & 30 & 8 \\
\hline & \multicolumn{2}{|c|}{$\chi^{2}=17.63(0.000)$} & \multicolumn{2}{|c|}{$\chi^{2}=10.09(0.001)$} \\
\hline$<5$ & 64 & 67 & 81 & 69 \\
\hline \multirow[t]{2}{*}{$>=5$} & 33 & 8 & 16 & 6 \\
\hline & \multicolumn{2}{|c|}{$\chi^{2}=12.71(0.000)$} & \multicolumn{2}{|c|}{$\chi^{2}=2.73(0.098)$} \\
\hline$<10$ & 75 & 70 & 86 & 72 \\
\hline$>=10$ & 22 & 5 & 11 & 3 \\
\hline & \multicolumn{2}{|c|}{$\chi^{2}=8.19(0.004)$} & \multicolumn{2}{|c|}{$\chi^{2}=3.04(0.081)$} \\
\hline
\end{tabular}

Note: Cell entries are the number of countries in the associated income group satisfying the inequality implied by the cutoff value, $\chi^{2}$ is the sample value of the chi-square statistic and the entries in parenthesis are the prob-value of $\chi^{2}$.

Clearly, there is strong evidence that domestic terrorism is heavily concentrated in the lowest two income groups. For all three cutoff values, the null hypothesis of no difference between the income groups is rejected at conventional significance levels. The evidence is less strong for transnational terrorism. Countries with 2 or more transnational incidents tend to be the low income countries ( $\chi^{2}$ is 10.09 with a prob-value of 0.001 ). However, for the other cutoffs values shown in the table, at the $5 \%$ significance level, we cannot reject the null hypothesis that the distribution of transnational incidents depends is invariant to income. Although it could be that low- and high-income behave similarly regarding transnational incidents, very few countries experienced more than 5 incidents so that the distribution is thin for high cutoff values.

Of course, there may be other intervening variables so that it is necessary to use a multivariate framework to control for the influence of other determinants of terrorism. Simple linear regression models lead to the standard result in the literature that real GDP has no influence on the level of terrorism. Regardless of how GDP enters such regressions, it is never statistically significant at conventional significance levels. For example, consider Regression 1 (estimated by simple OLS) and Regression 2 (estimated as a negative binomial model) both containing the log of real per capita GDP and its square (in order to capture possible nonlinearity):

$$
\begin{gathered}
\hat{T}_{i}=-162.6+37.86 \operatorname{lgd} p_{i}-2.57(\operatorname{lgdp})^{2}+11.86 \operatorname{lpop}_{i} \\
(-1.23) \quad(1.10) \quad(-1.17) \\
\hat{T}_{i}=\exp \left[-4.75+0.58 \operatorname{lgdp}_{i}-0.05\left(\operatorname{lgdp}_{i}\right)^{2}+1.16 \operatorname{lpop}_{i}\right] ; \quad \eta=2.56 \\
(-1.11) \quad(0.45)
\end{gathered}
$$


where: $\hat{T}_{i}=$ estimated number of domestic terrorist incidents, $\operatorname{lgd} p=\log$ of real per capita GDP, lpop $=\log$ of population, $\eta^{2}=$ is the variance parameter of the negative binomial distribution, $i$ is a country subscript, and the $t$-statistics (constructed using robust standard errors) are in parentheses. ${ }^{1}$

In both instances, the coefficients for the log of real per capita $G D P$, and its square, are statistically insignificant. Moreover, the prob-value for the joint test that both of the income coefficients equal zero is 0.170 for Regression 1 and 0.658 for Regression 2. As such, the type of nonlinearity exhibited in Figure 1 is not readily captured by a polynomial in the log of real per capita GDP.

In order to better account for any differences across the income groups, we first estimated separate negative binomial models for countries in the lower of the two World Bank income categories and for countries in the higher two categories. Consider the following regression for countries in the lower income grouping

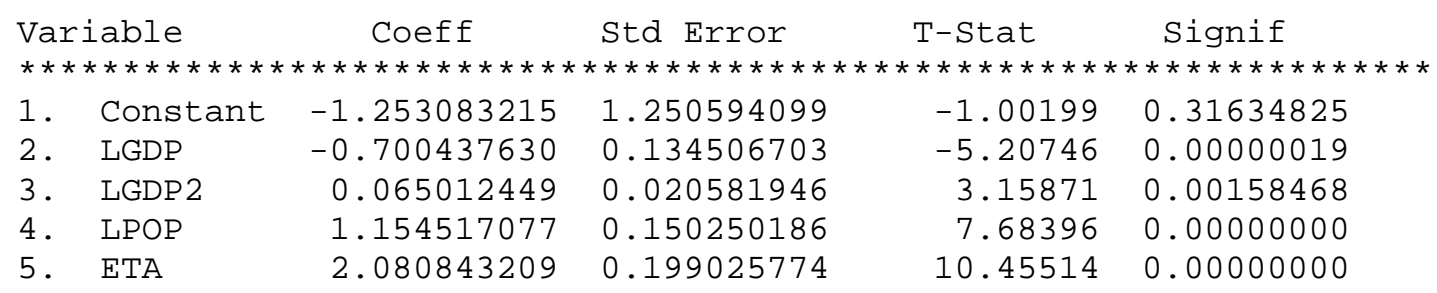

and for countries in the higher grouping

\begin{tabular}{|c|c|c|c|c|}
\hline $\begin{array}{l}\text { Variable } \\
\star * \star * \star * *\end{array}$ & $\underset{* * * * * * *}{\text { Coeff }}$ & 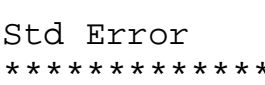 & $\begin{array}{l}\mathrm{T}-\text { Stat } \\
* * * * * * * * *\end{array}$ & $\underset{* \star \star}{\text { Signif }}$ \\
\hline Constant & -77.51054238 & 10.30571954 & -7.52112 & ๑. . \\
\hline LGDP & 15.63139993 & 2.38869578 & 6.54391 & 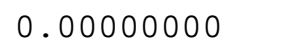 \\
\hline LGDP2 & -0.83964235 & 0.14387575 & -5.83589 & $\odot .0 \odot \odot \odot \odot \odot \odot 1$ \\
\hline LPOP & 1.45603231 & $\odot .21715 \odot 26$ & 6.70518 & $\odot . \odot \odot \odot \odot \odot \odot \odot \odot$ \\
\hline ETA & 4.31317122 & $\odot .75489886$ & 5.71357 & $\odot . \odot \odot \odot \odot \odot \odot \odot 1$ \\
\hline
\end{tabular}

The point is that for both sets of countries, $\operatorname{lgd} p_{i}$ is an important determinant of the level of domestic terrorism. The exclusion restriction for the null hypothesis that the coefficients of $\operatorname{lgd} p_{i}$ and $\left(\operatorname{lgd} p_{i}\right)^{2}$ are both equal to zero yields a $\chi^{2}$ value of 27.163 (prob-value $\left.=0.000\right)$ for the first regression and 48.097 (prob-value $=0.000$ ) for the second. A test of coefficient equality

\footnotetext{
${ }^{1}$ Throughout the paper, each model was estimated using a Poisson as well as a negative binomial distribution. Since the Poisson models always showed excess volatility, they are not reported here.
} 
across equations yields a $\chi^{2}$ value of 35.852 (prob-value $=0.000$ ) so that it is more than reasonable to conclude that the coefficients are significant and differ across equations. ${ }^{2}$

A downside of the threshold models is that the effect of income on terrorism is likely to be smooth, rather than taking on a discrete jump at the threshold. ${ }^{3}$ To illustrate the point, the sharp break between the low and high income countries means that Ethiopia and Brazil are in the low income group while and South Africa and Luxemburg are in the high income group. Nevertheless, Brazil and South Africa have very similar levels of per capita income. As such, a smooth transition regression model that allows for a gradual adjustment of the regression coefficients seems most appropriate. Consider:

$$
\hat{T}_{i}=\exp \left[\left(\alpha_{0}+\alpha_{1} \operatorname{lgd} p_{i}+\alpha_{2} \operatorname{lgdp_{i}^{2}}+\alpha_{3} \operatorname{lpop}_{i}\right)+\theta\left(\beta_{0}+\beta_{1} \operatorname{lgdp_{i}}+\beta_{2} \operatorname{lgdp_{i}^{2}}+\beta_{3} \operatorname{lpop}_{i}\right)\right]
$$

where $\theta$ has the logistic form

$$
\theta=\left[1+\exp \left(-\gamma\left(\lg p_{i}-c\right)\right)\right]^{-1} \quad ; \gamma>0
$$

In a sense, the smooth transition model splices together two separate regressions. When $\operatorname{lgd} p_{i}$ is equal to the centrality parameter $c, \theta=0.5$ so that the relationship in (3) becomes

$$
\hat{T}_{i}=\exp \left\{0.5\left[\left(\alpha_{0}+\beta_{0}\right)+\left(\alpha_{1}+\beta_{1}\right) \operatorname{lgd} p_{i}+\ldots\right]\right\}
$$

However, for countries such that $\operatorname{lgd} p_{i}$ is far below $c$, the value of $\theta$ approaches 0 so that (1) approaches $\hat{T}_{i}=\exp \left[\alpha_{0}+\alpha_{1} \operatorname{lgdp_{i}}+\ldots\right]$ and for countries such $\operatorname{lgdp_{i}}$ is far above $c$, the value of $\theta$ approaches 1 so that (1) approaches $\hat{T}_{i}=\left[\left(\alpha_{0}+\beta_{0}\right)+\left(\alpha_{1}+\beta_{1}\right) \operatorname{lgdp_{i}}+\ldots\right]$. The point is that the transition between the two equations is smooth. ${ }^{4}$ Moreover, since the transition is smooth, we

\footnotetext{
${ }^{2}$ We also estimated threshold models using Chan's method of finding a consistent threshold estimate. a consistent estimate of the threshold (i.e., the cutoff between low and high income countries) using the grid search method detailed in Enders (2010). The estimated cutoff was $\lg d p_{i}$ $<6.69$ (i.e., countries with an average value of GDP less than $\$ 804$ per year). Although this is far lower than the World Bank's cutoff value, we still found a significant relationship between terrorism and income for the low income nations.

${ }^{3}$ Moreover, our measure of output is an average that does not perfectly correspond to the 2007 World Bank classification since some countries moved from one income grouping to another. ${ }^{4}$ We also estimated smooth transition models such that $\theta$ has the exponential form: $\theta=1-\exp \left[-\gamma\left(\operatorname{lgd} p_{i}-c\right)^{2}\right]$. This exponential model imposes a U-shape (or an inverted U-shape) on the transition function. Such a specification would be appropriate if the very low- and highincome countries acted similarly while the middle income countries formed their own group. The exponential specification did not perform as well as the logistic specification so it is not reported here.
} 
do not need to impose (or estimate) a particular cutoff value. The estimated model using (3) and (4) is:

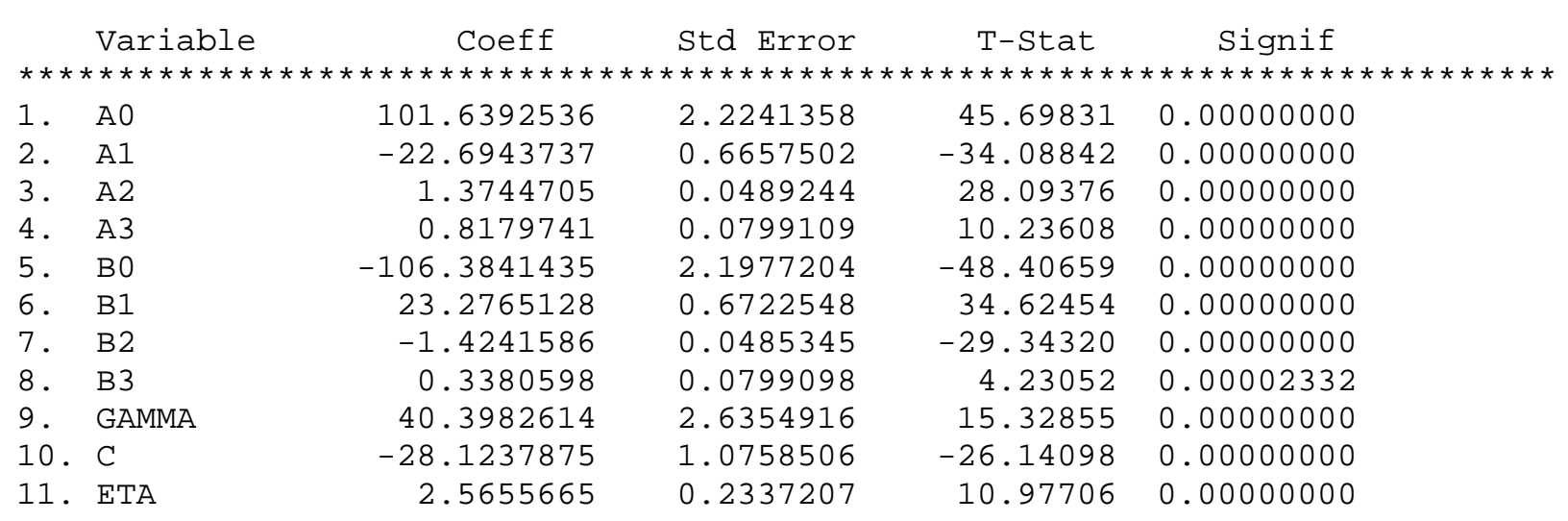

The income coefficients are all significant and the joint test for the null hypothesis that all coefficients of the income variables are jointly equal to zero is significant at any conventional level. Since the model is highly nonlinear, it is difficult to interpret the response of terrorism to income levels just by examining the individual coefficients. However, if we evaluate lpop $_{i}$ at its mean value, we can trace out the response of terrorism to changes in $\lg d p_{i}$. As shown in Figure 2, increases in income have only a small effect on terrorism for the low income countries.

However, as the level of income increases, the level of terrorism begins to decline fairly steadily once $\operatorname{lgdp_{i}}$ exceeds 6.9 [so that per capita real GDP is approximately $\$ 1000 \cong \exp (6.9)$ ].

An important issue is whether the relationship between $\operatorname{lgd} p_{i}$ and income is robust to the presence of other regressors in the model. Unfortunately, a downside of nonlinear estimation methods is that convergence problems prevent estimating a model with a large number of variables that are potentially insignificant and/or are strongly correlated. Instead, we add other potential regressors to the logistic model one variable at a time (so that each equation contains four regressors: $\operatorname{lpop}_{i}, \operatorname{lgd} p_{i}, \operatorname{lgdp}_{i}^{2}$ and the additional variable) and test the significance of each. Consider:

\begin{tabular}{lccccc} 
Variable & $\boldsymbol{N}$ & $\boldsymbol{A I C}_{\boldsymbol{0}}$ & $\boldsymbol{A I C}_{\boldsymbol{x}}$ & prob $_{\boldsymbol{x}}$ & prob $_{\boldsymbol{I q d p}}$ \\
\hline Gini Coeff. & 122 & -140.6009 & -140.6157 & 0.002 & 0.000 \\
Freedom House & 170 & -168.0139 & -168.0263 & 0.002 & 0.000 \\
Polity & 170 & -168.0139 & -167.9973 & 0.002 & 0.000 \\
Rule of Law & 171 & -167.0340 & -167.0114 & 0.000 & 0.000 \\
Corruption & 171 & -167.0340 & -167.0382 & 0.737 & 0.000 \\
Unemployment & 142 & -197.2327 & -197.2407 & 0.000 & 0.000 \\
Education & 166 & -172.0424 & -171.2980 & 0.000 & 0.000 \\
\hline
\end{tabular}

where: $N=$ the number of usable observations when the variable in question is included in the model, $A I C_{0}=A I C$ without the included variable, $A I C_{x}=A I C$ with the included variable (for comparability $A I C_{0}$ and $A I C_{x}$ are obtained using the same sample of countries), prob $_{x}=$ prob- 
value that the two coefficients on the variable in question are jointly equal to zero, and $p r o b_{\text {lgdp }}=$ prob-value that the four coefficient on the log GDP variables are jointly equal to zero. Note that we calculate the $A I C$ as $-2 L / N+2 k / N$ where $k=$ number of estimated coefficients and $L$ is the maximized value of the log likelihood function without the constant terms. As such, variable $x$ is selected to be included in the model if $A I C_{X}<A I C_{0}$.

When we added the gini coefficient to the model, the number of usable observations $(N)$ dropped to 122 (we could not obtain Gini coefficients for 50 of the countries). For these 122 countries, the $A I C$ for the model without the gini coefficient $\left(\mathrm{AIC}_{0}\right)$ was -140.6009 whereas the AIC for the model with the gini coefficient $\left(\mathrm{AIC}_{\mathrm{x}}\right.$ ) was -140.6157. As such, the AIC selects the model with the gini coefficient. Moreover, the prob-value for the exclusion restriction that the coefficients on the gini coefficient were both equal to zero $\left(\right.$ prob $\left._{x}\right)$ was 0.002 . More importantly,

the prob-value of the $\chi^{2}$ test for the exclusion restriction that the coefficients on $\operatorname{lgd} p_{\mathrm{i}}$ and $\operatorname{lgdp_{i}}{ }^{2}$ are all jointly equal to zero was about 0.000 .

Given the nonlinearities in the model, the response of terrorism to any of the variables is not readily apparent by examining the model's coefficients. In Figure 3, we plot the response of terrorism to the gini coefficient evaluating the GDP and population variables at their mean values. It is important to note that terrorism is an increasing function of income inequality - as inequality rises the estimated number of domestic incidents in country $i$ increases from about 2 to about 15.

Both the AIC and significance tests indicate that the Freedom House variable and the unemployment rate both influence terrorism. However, the results with the other variables are mixed. Significance tests, but not the AIC, select models with Unemployment, Polity and the Rule of Law. The AIC, but not the significance tests, selects the model with Corruption. The key point, however, is that per capita GDP is always significant regardless of which other variables are included in the model.

\section{Results with Transnational Terrorism}

The results using transnational terrorism are similar to those using domestic terrorism. However, the magnitude of the effects are substantially reduced using transnational terrorism. Simple linear models in the form of (1) and (2) indicate no relationship between terrorism and income regardless of whether we use OLS, the Poisson or negative binomial models. Splitting the sample using the World Bank's classification scheme does indicate that the GDP variables are significant for both income groups regardless of whether the equations are estimated using the Poisson or the negative binomial distributions. When we replace the dependent variable in 3 and 4 with transnational incidents, for the low-income countries 


\begin{tabular}{|c|c|c|c|c|}
\hline Variable & Coeff & Std Error & T-Stat & Signif \\
\hline$A \odot$ & $-34,91149295$ & 10.56132001 & $-3,30560$ & ๑ 00094773 \\
\hline A1 & 9.51015333 & 2.78333046 & 3.41683 & 0.00063356 \\
\hline A2 & $-\odot .72808661$ & ๑.19882276 & -3.66199 & $\odot .00025027$ \\
\hline A3 & 1.07286155 & $\odot .30942561$ & 3.46727 & $\odot .0 \odot \odot 52578$ \\
\hline 5. ETA & 2.02137536 & ๑.26955366 & 7.49897 & 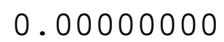 \\
\hline
\end{tabular}

and for the high-income countries

\begin{tabular}{|c|c|c|c|c|}
\hline$\underset{* \star * \star * \star * \star * \star *}{\text { Variable }}$ & $\underset{* * * * * *}{\text { Coeff }}$ & Std Error & $\begin{array}{c}\text { T-Stat } \\
\star * * * * * *\end{array}$ & $\underset{* * * * * * * * * * * * * * * * * *}{\text { Signif }}$ \\
\hline 1. $A \odot$ & -55.55112451 & 3.17922133 & -17.47319 & ๑. .००००००९ \\
\hline 2. $A 1$ & 11.67983886 & 0.01855453 & 629.48713 & $\odot . \odot \odot \odot \odot \odot \odot \odot \odot$ \\
\hline 3. $A 2$ & $-\odot .64151708$ & ๑. . 03016958 & -21.26370 & 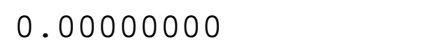 \\
\hline 4. $\mathrm{A} 3$ & 0.63011063 & 0.16707130 & 3.77151 & ๑. . 0016226 \\
\hline 5. ETA & 3.09130776 & 0.54930614 & 5.62766 & $\odot .00000002$ \\
\hline
\end{tabular}

The income variables are individually significant and the prob-values for the joint test that that $\alpha_{1}=\alpha_{2}=0$ are both less than 0.0002 . Figure 4 shows the response of domestic terrorism to income when we estimate the model using the logistic specification. In contrast to Figure 2, the relationship between income and terrorism seems to be highest in the lower middle income countries. The maximum value is reached when $\operatorname{lgdp}_{i}$ is 7.703 or when per capita GDP is about $\$ 2215$. Nevertheless, the response is quite small; the effect of GDP on terrorism is never more than 1.7 incidents over an eight year period.

Notice that the shape of the transition function explains why linear specifications fail to capture the relationship between transnational terrorism and poverty. Obviously, linear specifications cannot capture the highly nonlinear relationship shown in Figure 4. The correlation coefficient (a measure of linear association) between the two variables is only -0.159 .

\section{Conclusions}

The strong conclusion from the terrorism literature is that there is no relationship between terrorism and per capita GDP. This finding is supported by Gassebner and Luechinger's (2011) careful review of the literature and by their estimating millions of regression equations with various combinations of explanatory variables. They conclude that population and various measures of political freedom (e.g., the Polity or Freedom House Index) are robust explanatory variables for terrorism. Yet, in spite of the vast literature on the determinants of terrorism, there has not been a careful examination of a nonlinear relationship between poverty and terrorism. Nor have such studies decomposed terrorism into domestic versus transnational events. We find a strong nonlinear relationship between income and terrorism. Regarding domestic terrorism, the relationship is generally negative; whereas for transnational terrorism, the effect is bell-shaped. Since increases in per capita GDP tend to increase terrorism (until per capita GDP reaches 
\$2215) and then decrease terrorism, a linear regression of terrorism on per capita income will tend to find the absence of any meaningful relationship between the two variables. This relationship is robust to the presence of other explanatory variables in the model. We also find that countries with high levels of income inequality (as measured by the gini coefficient) tend to have high levels of terrorism.

It is important to understand the nature of the nonlinearities present in the two types of terrorism. As nations develop, the level of domestic terrorism they experience is likely to decline once their real per capita GDP passes a threshold of about $\$ 1000$. However, if development is accompanied by an increase in income inequality, domestic terrorism could increase. Regarding transnational terrorism, economic development is predicted to increase the number of transnational incidents until per capita GDP reaches a threshold of about \$2215. Clearly, nations providing development assistance need to be aware that their efforts might actually increase the number of attacks directed at their interests. As such, it is especially important to be concerned about constructing a development plan that does not exacerbate income inequality.

\section{REFERENCES}

Abadie, Alberto. 2006. "Poverty, Political Freedom and the Roots of Terrorism," American Economic Review, 96(2), 50-6.

Block, M.K.; and J.M. Heineke. 1975. "A Labor Theoretic Analysis of the Criminal Choice," American Economic Review, 65(3), 314-325

Brush, Jesse. 2007. "Does Income Inequality Lead to More Crime? A Comparison of CrossSectional and Time-Series Analyses of United States Counties,” Economics Letters, 96(2), 264-268.

Choe, Jongmook. 2008. “Income inequality and crime in the United States," Economics Letters, 101(1), 31-33.

Crenshaw, Martha. 1981. "The Causes of Terrorism," Comparative Politics, 13(4). 379-399.

Enders, Walter; Todd Sandler and Gaibulloev, Khusrav. 2011. "Domestic versus Transnational Terrorism: Data, Decomposition, and Dynamics.” Journal of Peace Research, 48(3): 319-337.

Gassebner, Martin; Simon Luechinger. 2011. "Lock, Stock, and Barrel: A Comprehensive Assessment of the Determinants of Terror," Public Choice, 149, 235-61.

Krueger, Alan B. and Jitka Maleckova. 2003. "Education, Poverty, and Terrorism: Is There a Causal Connection?,” Journal of Economic Perspectives, 17(4), 119-44.

National Consortium for the Study of Terrorism and Responses to Terrorism. 2009.Global Terrorism Database: GTD Variables \& Inclusion Criteria, Version 3.0, START,University of Maryland (http://www.start.umd.edu/gtd/downloads/Codebook.pdf).

Piazza, James A. 2006. "Rooted in Poverty?: Terrorism, Poor Economic Development, and Social Cleavages,” Terrorism and Political Violence, 18, 159-177. 


\section{Figure 1: Scatter Plots of Terrorism and Income}
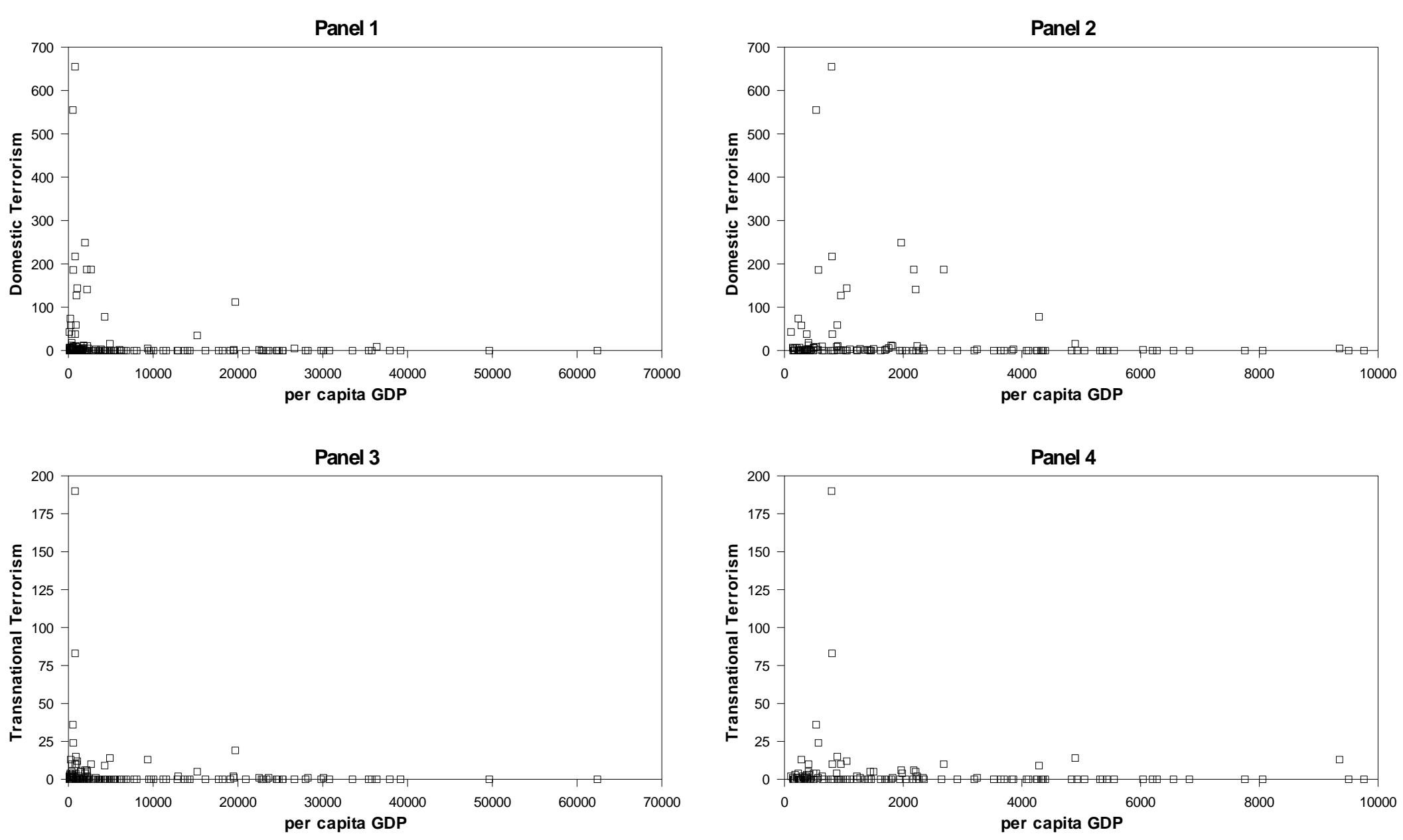


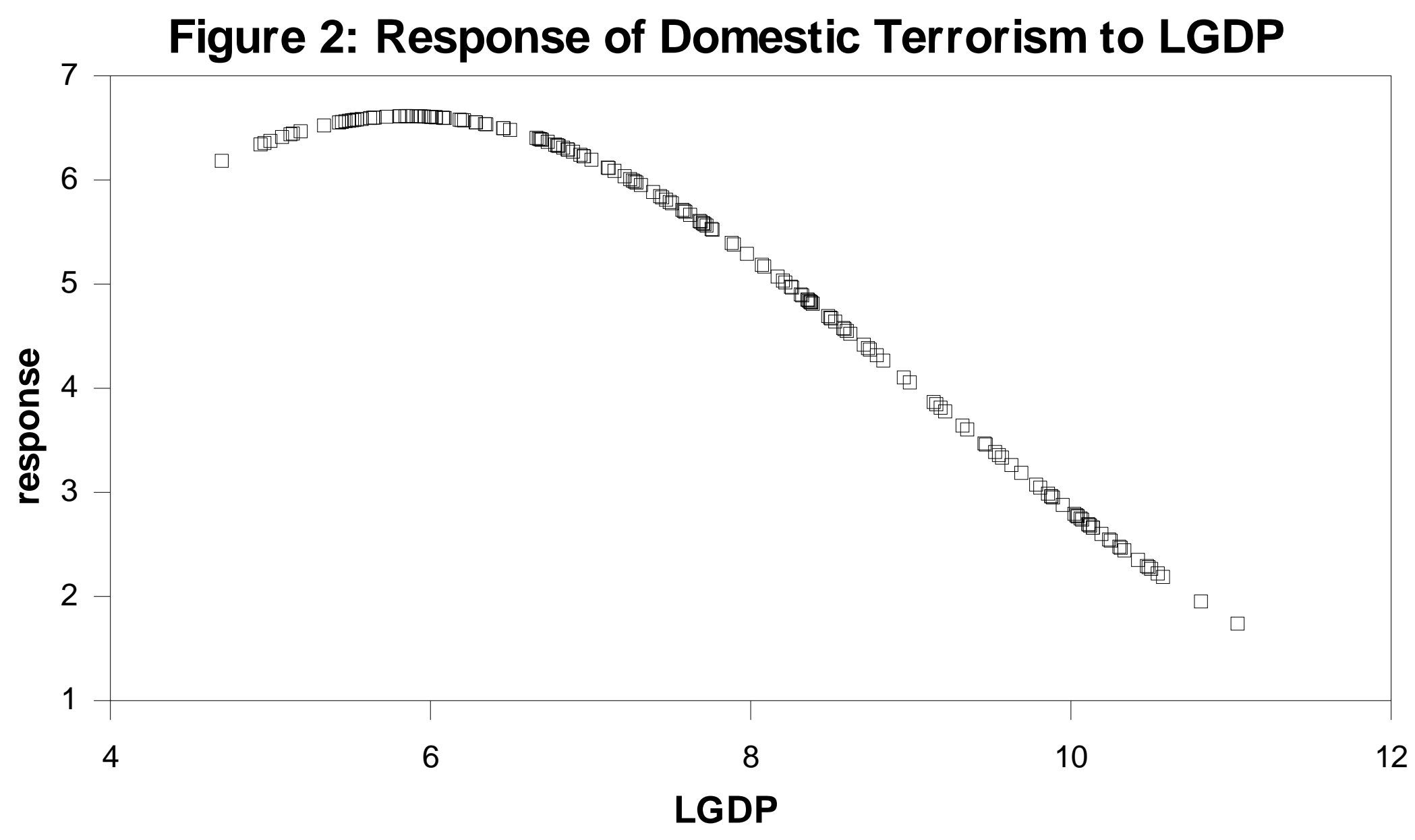


Figure 3: Response of Domestic Terrorism to Income Distribution

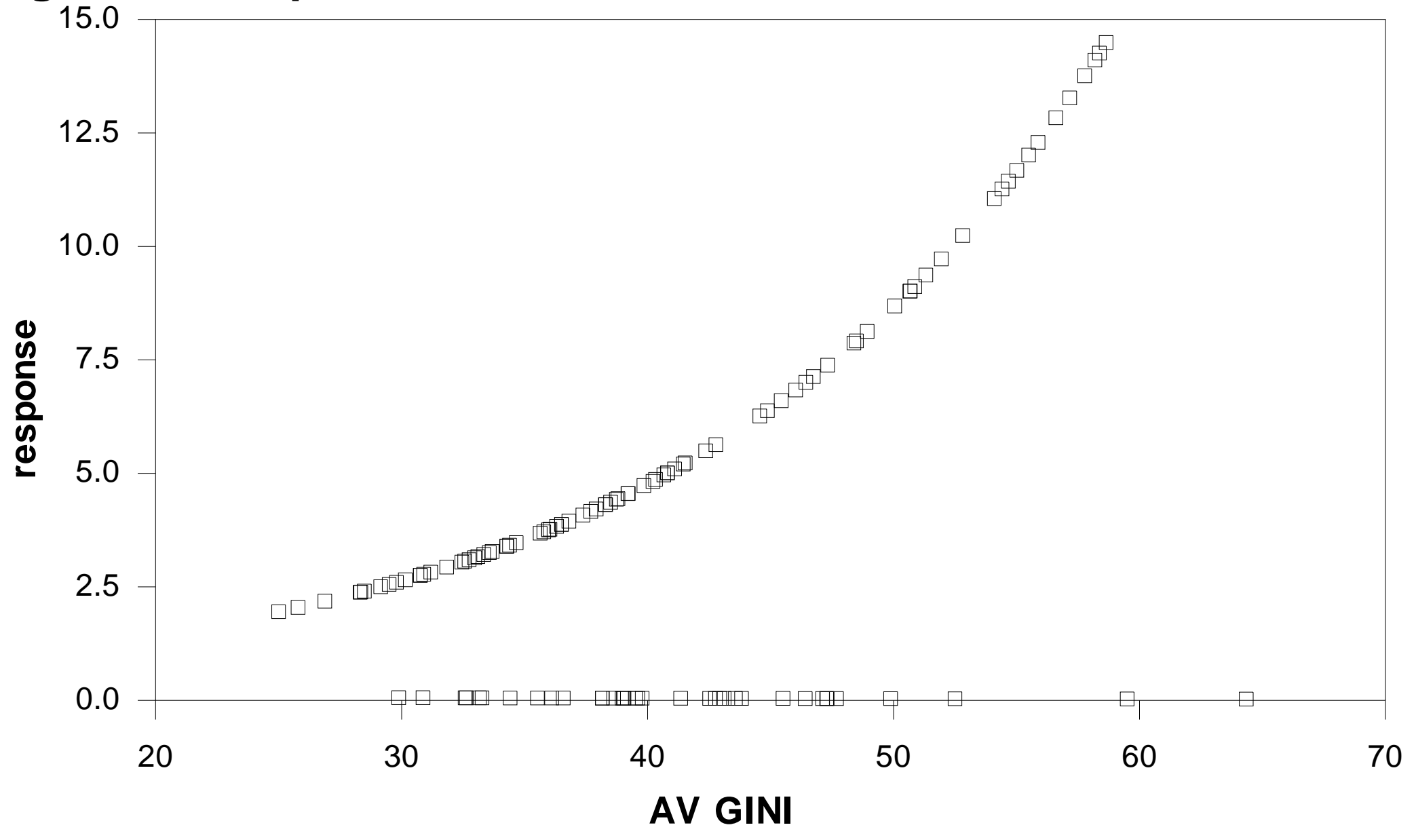


Figure 4: Response of Transnatinal Terrorism to LGDP

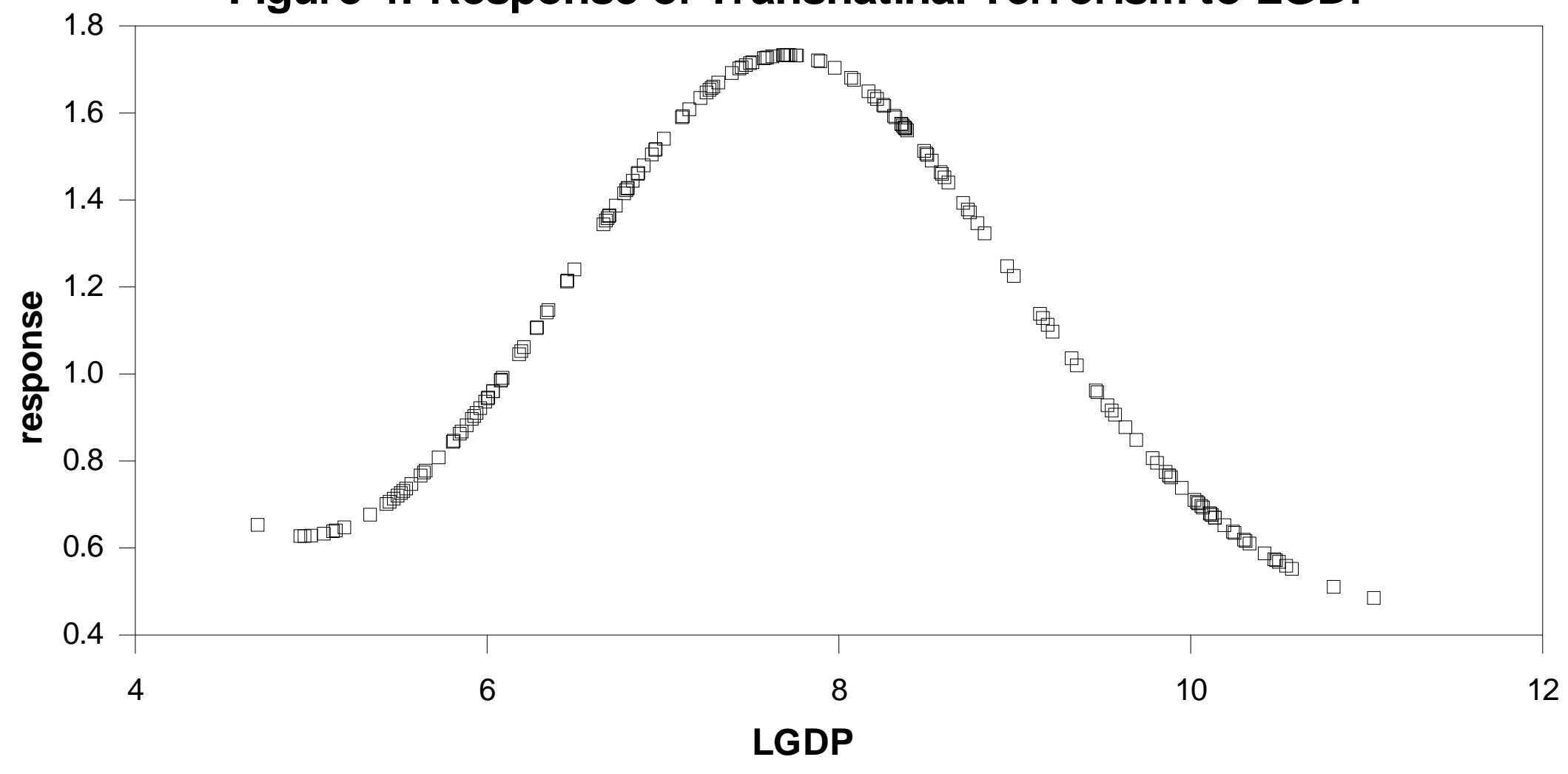

